\title{
TAHSP:-
}

The Internet Joutnal of Allied Health Sciences and Practice

A Peer Reviewed Publication of the College of Health Care Sciences at Nova Southeastern University

Dedicated to allied health professional practice and education

http://ijahsp.nova.edu Vol. 11 No. 1 ISSN 1540-580X

\section{Preparing Occupational Therapy and Physiotherapy Students for Work-Related Practice: A Clinical Education Initiative at One Australian University}

\author{
Kerry Adam, B App Sc ${ }^{1}$ \\ Jenny Strong, $\mathrm{PhD}{ }^{2}$ \\ Lucinda Chipchase, M App Sc, PhD³
}

1. Clinical Teacher, School of Health and Rehabilitation Sciences, The University of Queensland, Brisbane, Queensland

2. Professor of Occupational Therapy, School of Health and Rehabilitation Sciences, The University of Queensland, Brisbane, Queensland

3. Senior Lecturer, School of Health and Rehabilitation Sciences, The University of Queensland, Brisbane, Queensland

Australia

CITATION: Adam K, Strong J, Chipchase L. Preparing Occupational Therapy and Physiotherapy Students for Work-Related Practice: A Clinical Education Initiative at One Australian University. The Internet Journal of Allied Health Sciences and Practice. Jan 2013. Volume 11 Number 1.

\begin{abstract}
Purpose: Despite increasing numbers of novice occupational therapists (OTs) and physiotherapists (PTs) entering work-related practice since the early 2000s, clinical learning opportunities are often limited due to legal and insurance issues. In response, clinical educators at The University of Queensland, Australia, developed an industry consultancy service to provide clinical learning for students in this field. Students delivered injury prevention services with supervision from experienced educators. This paper describes the program and an evaluation of student learning. Method: Twenty-six students (10 OTs and 16 PTs) participated voluntarily in an evaluation of the program during 2008 and 2009. Surveys pre and post-placement included open and closed questions that sought students' knowledge of work-related practice and perceptions of practitioner roles. Knowledge was assessed with 20 questions on work-related practice. Differences in knowledge before and after the placement were analysed with non-parametric statistics. Open ended responses were subject to manual thematic analysis. Results: Students demonstrated a good understanding of the roles and tasks undertaken by practitioners in this field pre-placement. Their knowledge of work-related practice significantly increased following the placement $(p<0.05)$. Half of the students reported that their expectations for the placement had been met. Open ended responses provided students' perceptions of the program, both positive and negative. Conclusions: This clinical learning experience in work-related practice for OT and PT students provided a novel practical experience. Students demonstrated a good understanding of professional roles in the field and post-placement increased their understanding of work-related practice. The model provided a valuable method that ensures OT and PT students experienced work-related practice prior to graduation.
\end{abstract}

\section{INTRODUCTION}

Field based learning is a fundamental component of entry-level training in occupational therapy (OT) and physiotherapy (PT). ${ }^{1-5}$ Clinical learning provides opportunities whereby students put the skills and knowledge of the discipline into a real life practice setting. ${ }^{6-8}$ Such "real-life" experience should cover core areas of practice across the life span in different clinical contexts. ${ }^{9,10}$

One clinical context is work-related practice, an expanding professional area for OTs and PTs. ${ }^{11-14}$ Growth in this field is due to changes in legislation that required employers to maintain a healthy and safe workplace for workers by injury prevention, treatment, and rehabilitation. ${ }^{15}$ Clinical learning in this field would therefore be of benefit to entry level students prior to graduation. ${ }^{16,17}$ However, clinical learning opportunities in work-related practice are often limited. ${ }^{16,17}$ This is due to therapists 
frequently being sole practitioners with limited time to supervise or support students. ${ }^{18}$ In addition, concerns have been expressed by insurance companies regarding student involvement in client interventions that involve litigation.

To ensure OT and PT students received a clinical learning experience in work-related practice, The University of Queensland established a novel industry consultancy service based at the university. This paper describes the program and the perspectives of students. It evaluates their understanding of work-related practice and the roles and tasks of professionals in the field.

\section{The Work-Related Practice Clinical Learning Program}

The program was established to provide clinical learning in work-related practice to OT and PT students prior to graduation. The intention was to provide students with experience planning and delivering injury and risk identification and prevention services for industry clients. A university clinic was designed to create "real-world" projects for students. This was achieved by promoting the service to employers and managers in workplaces in the public and private sectors. Marketing included promoting the service as the UQ Work Service with the catch phrase "Work Well - Live Well" (Figure 1).

\section{Figure 1. Marketing to Industry Employers}

\section{UQ Work Service Model}
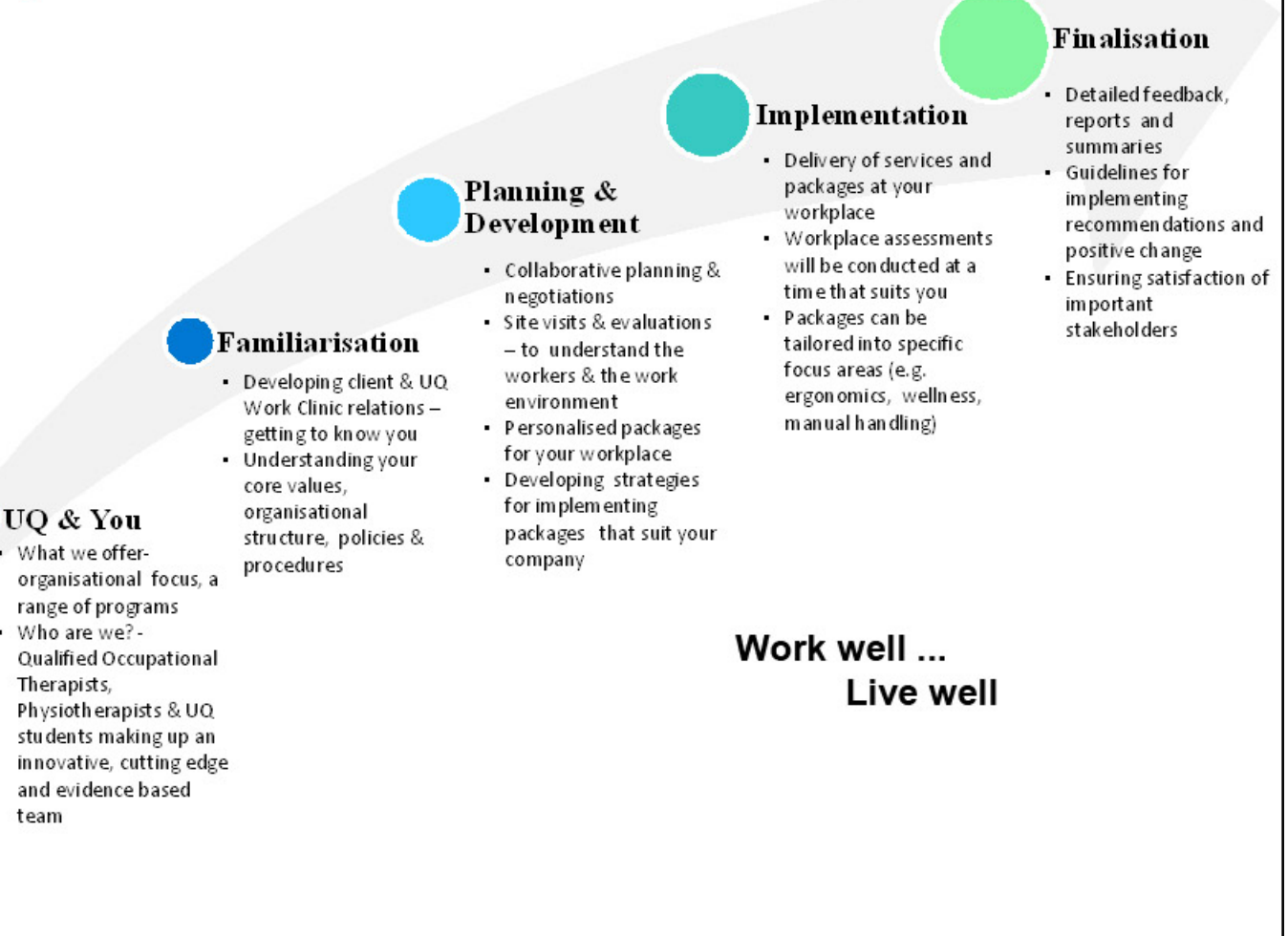

The service was marketed as a student service. Competitively priced student services were attractive to industry as final reports of assessments and recommendations were endorsed by experienced OT and PT educators. Local injury management service providers indicated limited interest in providing this service due to the significant cost to employers and the time required. Therefore, the student service was not viewed as a competitor by local practitioners. This was an important issue for educators as a long-term goal was to encourage external providers to consider student placements in the future.

\section{Operational Model}

The clinic operational model (Figure 2) evolved using features of the collaborative and inter-professional models of clinical education.2,19,20 The collaborative model is where two or more students work together with educators. This model closely resembles an everyday working environment facilitating communication between health professionals. ${ }^{21,22}$ The inter-professional environment allowed students to appreciate the contribution of other professionals in work-related practice. This environment 
accurately reflected the context of service delivery in the field..$^{23}$ The operational model enabled clinic staff to manage the complexity and intensity of communication required between students and educators. In addition, the model allowed staff to respond effectively to industry opportunities so that students could deliver client centred services. ${ }^{24}$

Figure 2. UQ Work Service Clinic Operational Model: Collaborative and Inter-Professional Setting

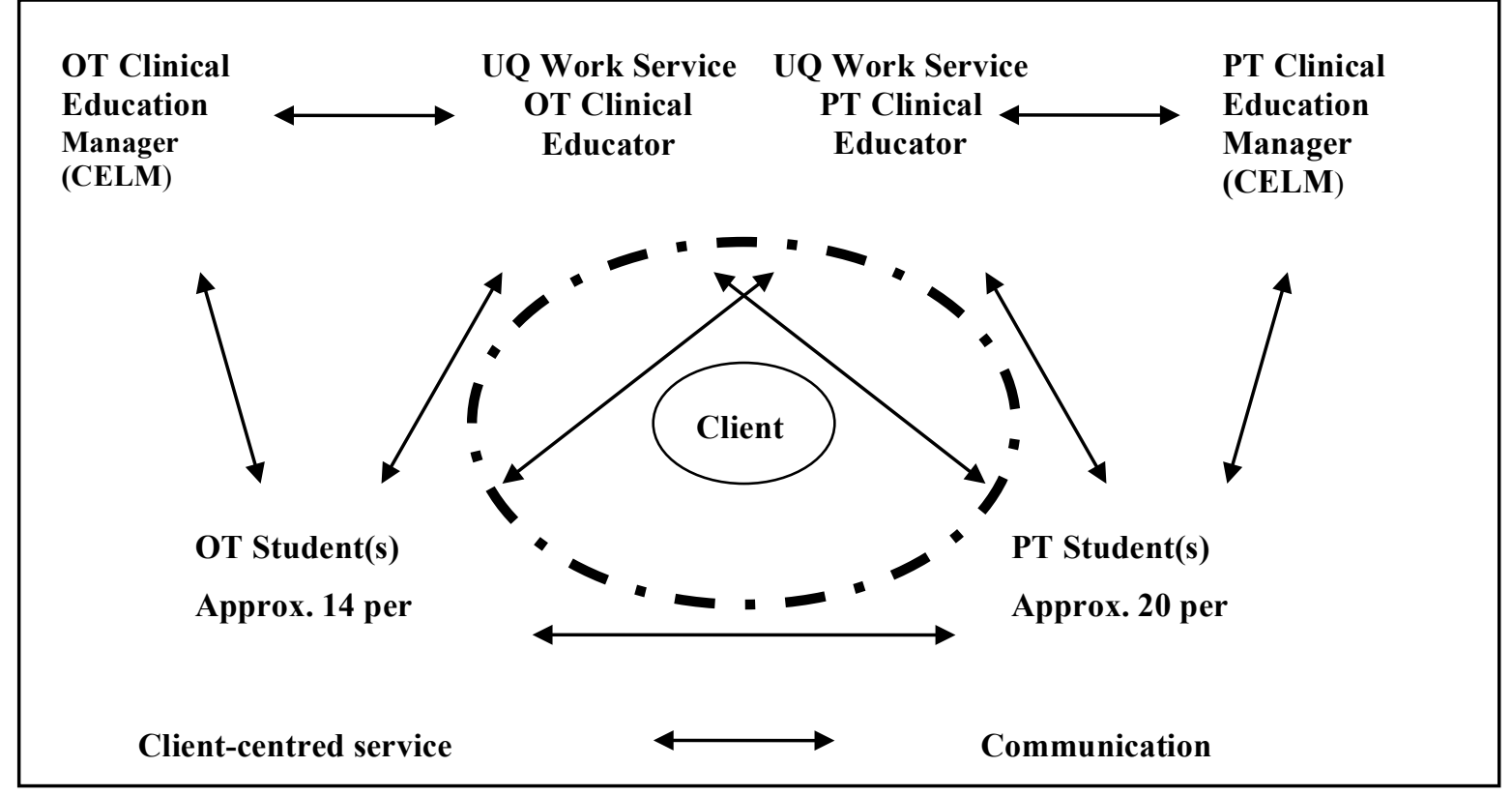

\section{Service Development}

Service development activities undertaken by the students were based on the Person-Environment-Occupation (PEO) Model. 25 The model provided a framework for understanding work place phenomena. ${ }^{26}$ The model facilitated a systematic approach to undertake worker and workplace assessment within each model segment (person-environment-task). Services were provided to industry sectors including manufacturing, security, healthcare and community services, and public and private sector administration. The PEO model guided students through service development which included activity analysis and risk assessment of individual occupational demands. ${ }^{25}$ Identified job demands were confirmed with workers and supervisors. Students then prepared musculoskeletal risk identification presentations for specific work sites and occupations. These included dental professionals, armoured vehicle drivers, and food and pharmaceutical packaging workers. Preparation required students to spend time at the work site undertaking observation, recording (photographs, videos, and discussion with workers and supervisors), and consideration of job demands. Educators encouraged an evidence based approach to service development activities. For example, the services used previously and their effectiveness in the workplace were considered along with the current evidence. Students searched for evidence in the professional literature using appropriate terms when preparing workplace presentations on particular topics. In addition, each student had an opportunity to lead a project and be a team member on other projects. Students were assessed mid-way and at completion of the placement using discipline specific assessment criteria.

\section{Service Delivery}

Students delivered a range of material for injury and illness prevention programs. Material included audio-visual presentations (using worksite photos or videos), written material, and reminder cards (such as Stretching at Work or Sun Safety). Material was based on the task, activity analyses, and risk assessments recorded for each occupation and workplace. For example, there were often multiple occupations, such as specialist dentists, dental therapists, and assistants, with different job demands at the one workplace. In addition, service delivery required a number of management and co-ordination activities that challenged students. These included leading and managing teams, preparing presentations within time limits and being available at times suitable to workers and employers (shift-work). Students were required to liaise with employers in order to schedule presentations for all staff on each shift to participate. Students also needed to obtain consent for photography or video of work processes or individuals. In addition, students were required to collect equipment for visits and presentations and to complete all paperwork following client services. Employers were not concerned that students required additional time to complete injury and risk assessment projects as they were ultimately vetted and endorsed by experienced practitioners. 


\section{EVALUATION}

The program was evaluated from March to November 2009. Ethical approval was obtained from the relevant ethics committee at The University of Queensland (Approval No. 2009000751).

\section{Student Participants}

All students $(n=26)$ who had been allocated to the placement participated in the evaluation. All PTs in the sample $(n=16)$ were enrolled in a Bachelor of Physiotherapy program. Eight OT participants were enrolled in a Bachelor of Occupational Therapy program while two were enrolled in a graduate entry Master of Occupational Therapy program $(n=10)$. The majority $(69.2 \%)$ of the participant sample $(n=26)$ were aged between 21 and 23 years.

\section{Evaluation Instrument}

The evaluation sought to describe the perspectives of students, their understanding of work-related practice, and the roles and tasks of professionals in the field. Semi-structured surveys were used to collect data anonymously from OT and PT students pre and post the work-related practice placement. The surveys included open and closed ended questions that were developed from the clinic teaching plan and clinic occupational health and safety (OHS) standard definitions document. The questionnaire included a set of 20 closed ended questions on work-related practice activities (Table 1), which were completed pre and postplacement. These questions were designed to ascertain students' knowledge on work-related practice information provided during the placement. Two open ended questions pre-placement sought to ascertain students' understanding of the roles of PTs and OTs in work-related practice and their expectations for the placement. One closed ended question post-placement asked if student expectations for the placement had been met. Finally, two open ended questions post-placement aimed to determine students' awareness of work-related practice and the roles graduates in the profession undertook.

\section{Table 1. Twenty Work-Related Practice Questions}

\begin{tabular}{|c|c|}
\hline No. & Questions \\
\hline 1. & Pre-existing musculoskeletal injuries are a good indication that a worker should not be asked to do any manual tasks. \\
\hline 2. & $\begin{array}{l}\text { When selecting assessments for injured workers, OTs and PTs should only include those that simulate their previous } \\
\text { job. }\end{array}$ \\
\hline 3. & It is important for injured workers to return to work as soon as possible doing other tasks with their colleagues. \\
\hline 4. & $\begin{array}{l}\text { Supervisors are the best people to ask about risks in the workplace as they have the best understanding of the risks to } \\
\text { which a worker is exposed. }\end{array}$ \\
\hline 5. & Psychological issues may not be important when an injured worker is physically able to return to their own job. \\
\hline 6. & Case management of an injured worker is based on the most financially effective outcome. \\
\hline 7. & Workplace interventions based on good evidence may be found in Advisory Standards. \\
\hline 8. & Suitable Duties Programs (SDP) must be designed by a health professional. \\
\hline 9. & $\begin{array}{l}\text { Codes of Practice (COP) provide workers, employers, and industry with guidance only about their jobs and are not } \\
\text { mandatory. }\end{array}$ \\
\hline 10. & Workers' Compensation insurance covers treatment and rehabilitation costs for injuries at work. \\
\hline 11. & $\begin{array}{l}\text { Communication with other treating professionals will assist in letting them know that your treatment should be } \\
\text { undertaken first. }\end{array}$ \\
\hline 12. & All workers need a Functional Capacity Evaluation (FCE) before they commence a return to work program. \\
\hline 13. & $\begin{array}{l}\text { Communication of information about work-related issues should take account of the other stakeholder's role in the } \\
\text { process. }\end{array}$ \\
\hline 14. & Communicating with other treating professionals should be done in writing. \\
\hline 15. & $\begin{array}{l}\text { Observing a task a worker is performing will provide enough information for the health professional to assess job } \\
\text { demands. }\end{array}$ \\
\hline 16. & Functional Capacity Evaluations (FCE) may tell us about the ability and impairment of injured workers. \\
\hline 17. & Reports about the injured worker or client may be accessed as part of legal processes without consent. \\
\hline 18. & Training is the first option that should be used in preventing risk of injuries. \\
\hline 19. & $\begin{array}{l}\text { Health professionals should rely on the employer's view as they are paying the Workers Compensation insurance } \\
\text { premiums. }\end{array}$ \\
\hline 20. & $\begin{array}{l}\text { I will be able to provide my report directly to an employer as they will have access to all the medical information ab } \\
\text { injured employee. }\end{array}$ \\
\hline
\end{tabular}

Process of Evaluation

Students who agreed to participate selected a random identifying number to support anonymity for the pre-placement survey. 
They were requested to keep and reuse this identifying number on the post-placement survey. Pre-placement surveys were sealed in the envelope provided and placed in a sealed collection box by participants. At placement completion, participating students completed the post-placement survey using the individual identifier numbers provided earlier. Data were entered and analysed only after individual participants had completed the placement.

\section{Data Analysis}

The data were entered into the Statistical Package for the Social Sciences. ${ }^{27}$ Demographic data were tabulated. Responses to the set of 20 knowledge questions were categorised as either correct or incorrect. As this was nominal data, changes to scores pre and post-placement for each of the 20 questions were determined using McNemar's test. ${ }^{28}$ In addition, each participant was given an overall knowledge score out of 20. Changes pre and post-placement to participants' total scores were analysed with the Kruskall Wallis test. ${ }^{28}$ This non-parametric test was selected as the data were ranked. ${ }^{29}$ The $p$-value threshold for significance of results was less than 0.05 .

Responses to open ended questions were thematically analysed using a systematic examination of the text seeking recurrence of words and phrases and then applying codes. On the basis of the codes, themes were then identified based on similar groups of codes. ${ }^{30}$

\section{FINDINGS}

The median total score for the knowledge questions significantly improved from 11 before the placement to 14 after the placement $(p<0.01)$. This change was largely due to significant improvement in five of the 20 work-related practice questions from pre to post-placement (Table 2).

Table 2. Changes to Individual Response Scores Pre and Post-Placement $\left.{ }^{*}<0.05\right)$

\begin{tabular}{|l|l|l|l|}
\hline Questions & $\begin{array}{l}\text { Correct responses } \\
(n=24)\end{array}$ & $\begin{array}{l}\text { Correct responses } \\
(n=24)\end{array}$ & $\begin{array}{l}\text { McNemar's } \\
\text { P value }\end{array}$ \\
\hline & Pre-placement & Post-placement & \\
\hline 1 & 14 & 16 & 0.75 \\
\hline 2 & 16 & 11 & 0.13 \\
\hline 3 & 19 & 20 & 1.00 \\
\hline 4 & 18 & 17 & 1.00 \\
\hline 5 & 24 & 21 & 0.25 \\
\hline 6 & 13 & 17 & 0.29 \\
\hline 7 & 5 & 12 & $0.02^{*}$ \\
\hline 8 & 6 & 17 & $0.01^{*}$ \\
\hline 9 & 5 & 20 & $0.00^{*}$ \\
\hline 10 & 19 & 22 & 0.38 \\
\hline 11 & 8 & 7 & 1.00 \\
\hline 12 & 3 & 11 & $0.01^{*}$ \\
\hline 13 & 18 & 21 & 0.45 \\
\hline 14 & 5 & 6 & 1.00 \\
\hline 15 & 20 & 21 & $1.00-$ \\
\hline 16 & 20 & 22 & 0.63 \\
\hline 17 & 6 & 10 & 0.29 \\
\hline 18 & 10 & 18 & $0.04^{*}$ \\
\hline 19 & 21 & 22 & 1.00 \\
\hline 20 & 16 & 17 & 1.00 \\
\hline
\end{tabular}

\section{Thematic Analyses}

Responses to open ended questions pre and post-placement were analysed thematically. Data from each participant were given a numerical code (S1, S2 etc.) prior to analysis and any mention of the students or staff was de-identified. The questions asked students their perceptions of the roles and tasks that therapists in work-related practice undertake with a similar question postplacement. In addition, during pre-placement, students were asked to outline their expectations for the placement. Themes which were identified described students' perceptions. Post-placement students were asked if these expectations had been met. 


\section{Therapists' Roles and Tasks in Work-Related Practice Pre and Post-Placement}

All pre-placement participants $(n=26)$ responded to the question "What do therapists do in work-related practice?" Three themes were identified: 1) Injury treatment and rehabilitation, 2) Assessment including task analysis and risk assessment, and 3) Training and education for health promotion and injury prevention. Themes and sub-themes from open-ended questions are presented in Table 3.

Table 3. Thematic Analysis: Open Ended Question

\begin{tabular}{|c|c|c|c|}
\hline Question & What do therapists do in work-rel & ted practice? (n=26) & \\
\hline Themes & $\begin{array}{l}\text { Injury treatment and rehabilitation } \\
(n=18)\end{array}$ & $\begin{array}{l}\text { Assessment including task and } \\
\text { risk analysis }(n=19)\end{array}$ & $\begin{array}{l}\text { Training and education for } \\
\text { health promotion and injury } \\
\text { prevention }(n=19)\end{array}$ \\
\hline $\begin{array}{l}\text { Sub- } \\
\text { themes }\end{array}$ & $\begin{array}{l}\text { Reduce injuries, facilitate } \\
\text { rehabilitation and transition into } \\
\left.\text { workplace ( }{ }^{*} \mathrm{~S} 3, \mathrm{~S} 19\right) \\
\text { Suitable duties plans and return to } \\
\text { work (S10, S17) } \\
\text { Make recommendations about } \\
\text { interventions in relation to work } \\
\text { occupations and environment (S8, } \\
\text { S15) } \\
\text { Encourage prevention and active } \\
\text { rehabilitation (S14, S21) } \\
\text { Involved in work rehabilitation of } \\
\text { people who have been injured at } \\
\text { work (S 26) } \\
\text { Administration related to injuries } \\
\text { and claims (S17,S 21) } \\
\text { Work as case managers to liaise } \\
\text { with key stakeholders for example; } \\
\text { general practitioners (S20). }\end{array}$ & $\begin{array}{l}\text { Help develop screening tools (S } \\
\text { 2) } \\
\text { Conduct assessment of } \\
\text { workplaces (S5, S9, S21) } \\
\text { Assess risk in workplaces (S3, } \\
\text { S6, S19, S23) } \\
\text { Job task analysis and functional } \\
\text { capacity assessments (S4) } \\
\text { Ergonomic assessments (S1, } \\
\text { S13, S16) } \\
\text { Assess risks and formulate } \\
\text { action plans (S1, S3, S4, S9) } \\
\text { Work screening assessments } \\
\text { (S18) } \\
\text { Strategies to decrease risk (S6, } \\
\text { S10, S11) }\end{array}$ & $\begin{array}{l}\text { Work with employers and } \\
\text { employees to develop } \\
\text { strategies to maintain a safe } \\
\text { and efficient work } \\
\text { environment (S11, S15) } \\
\text { Workplace and process } \\
\text { improvements to increase } \\
\text { worker satisfaction (S12) } \\
\text { Develop manuals (S22) } \\
\text { Develop information } \\
\text { programs and workshops } \\
\text { (S21) } \\
\text { Promote health and well- } \\
\text { being at the workplace (S13, } \\
\text { S14) } \\
\text { Make workplace safer for } \\
\text { employees (S10, S13). }\end{array}$ \\
\hline
\end{tabular}

Post-placement, perceptions of practitioner roles, and tasks $(n=23)$ were similar to those identified pre-placement. However, post-placement students identified an additional seven specialised roles and tasks in work-related practice. These roles were medico-legal assessors, rehabilitation co-ordinators, case manager, consultant to workplace, insurance case manager, and occupational health and safety officer.

\section{Student Expectations for Placement}

All pre-placement participants $(n=26)$ responded to a question seeking their expectations for the placement. Student expectations were not specific to work-related practice and themes were identified in the text. Themes were 1) Professional role modelling, 2) Client intervention expectations and 3) Gaining knowledge and skills, with a sub-theme of Improving Assessment capability.

Following the placement, $50 \%$ of participants $(n=24)$ reported that their expectations for the placement had been met. Two positive responses provided text including "I was able to get a glimpse and be involved with being a work-related therapist" (S1), and "I experienced a broad range of work related practice" (S25). However, the other $50 \%$ were not positive and reported that their placement expectations were not met. Students perceived a lack of support from educators. For example; "educators forced self-learning rather than assisting (me)" (S12) and "didn't have enough guidance especially early in the placement" (S2, S3). Five 
students reported that they had expected more client contact during the placement. Comments included "Expected more client contact" (S15, S17, S21, S22, S23), and "I didn't feel I was able to get a large degree of (client) experience" (S24). Other students reported dissatisfaction with the type of work offered during the placement. For example, one student commented "Learnt more to copy and paste than do more complex reasoning" (S17).

\section{IMPLICATIONS FOR CLINICAL LEARNING IN WORK-RELATED PRACTICE}

This paper has described a novel clinical learning experience in work-related practice. The program for OT and PT entry-level students was located on the University campus and reflected the inter-professional nature of work-related practice. The service operated similarly to other health service providers in work-related practice. Educators were able to establish worksite opportunities for students through industry networks. These opportunities allowed students to observe, reflect, and develop an understanding of work-related practice activities with the support of experienced educators. Thus, this model provided "real-life" experiences for students in a variety of industry settings with differing job demands and risks.

Following the placement, students' understanding of specific work-related practice information improved with changes to the total knowledge score significantly improving $(p<0.05)$. This was due to improved knowledge in five areas including the use of Advisory Standards, Suitable Duties Plans, Codes of Practice, Functional Capacity Evaluations, and training for injury prevention in work-related practice. However, student knowledge about "choice of assessments" decreased post placement. One possibility is that students may have been confused by other information provided during placement. Nevertheless, such improvement in understanding in these areas would support the students' entry-level preparedness and transition to practice in this field. Clearly, the clinical placement allowed students to contextualise existing and new knowledge about work-related practice.

Before the placement, students demonstrated a sound understanding of the roles and tasks for practitioners in work-related practice. Following the placement, students' understanding of roles increased as they were able to nominate specialist roles for practitioners including insurance case manager and rehabilitation coordinator to their roles and tasks. Additionally, students strongly agreed post-placement that they were aware of graduates working in this field and the roles and tasks expanded knowledge of practitioner roles. Clearly, the placement with the support of experienced educators provided a "real life" setting where students were able to improve their understanding of work-related practice. $1,17,31,32$

The expectations of the placement reported by students (e.g. modelling professional roles, client interventions, and knowledge achievement) would be expected in any field of clinical learning. ${ }^{6-8}$ Feedback indicated that the expectations of half of the students were met following the placement. For example, several students reported that they had expected more worksite activity. Two students felt that they did not receive enough direction while another two reported that the style of direction provided enabled them to work independently. This is an interesting finding that suggests that students may have been expecting the same type of direct supervision and hands-on client contact as provided in previous placements. ${ }^{33}$ Students may benefit from information prior to the placement about the style of client contact and how this differs from other clinical contexts. However, selfdirected learning may not have been suitable for some of the students. Learning styles and requirements may differ between students and according to Kolb, "Most of us develop learning abilities that emphasise some learning abilities over others". ${ }^{4}$

This novel placement was well received by industry. While the learning environment resulted in students taking longer time to complete projects, service costs for employers were low and clinical decisions and recommendations were endorsed by experienced clinicians. Workers also reported that they felt confident and comfortable with the students. The program provided an effective experience for OTs and PTs in this practice area.

\section{CONCLUSIONS}

This unique clinical learning program in work-related practice provided OT and PT students with information and practical experience at a time when community providers were unable to meet demand for placements in this field. Firsthand experience in this setting improved students' knowledge base and gave them an increased understanding of the roles and tasks required by practitioners in this field. In addition, the availability of educators at the university with access to industry networks and with experience in contemporary work-related practice added to the success of the program.

\section{REFERENCES}

1. Allison $\mathrm{H}$, Turpin MJ. Development of the student placement evaluation form: $A$ tool for assessing student fieldwork performance. Aus Occ Ther J. 2004;51(3):125-32.

2. Bartholomai S, Fitzgerald C. The Collaborative Model of Fieldwork Education: Implementation of the model in a regional hospital rehabilitation setting. Aus Occ Ther J. 2007;54:S23-S30. 
3. Crosbie J, Gass E, Jull G, Morris M, et al. Sustainable undergraduate education and professional competency. Aust J Physiother. 2002;48:5-7. [PMID 11869159]

4. Mulholland J, Mallik M, Moran P, et al. An Overview of the Nature of the Preparation of Practice Educators in Five Health Care Disciplines. Making Practice-Based Learning Work. ed. Geissler, P.C. Making Practice-Based Learning Work. 2002: 95.

5. Rindflesch AP, Dunfee HP, Cieslak KP, et al. Collaborative Model of Clinical Education in Physical and Occupational Therapy at the Mayo Clinic. J of Allied Health. 2009 Fall;38(3):132-42. [PMID 19753424]

6. Bjorklund A. Occupational therapy student's paradigms: A passage from beholder to practitioner. Aus Occ Ther J. 2000;47:97-109.

7. Hobbs C, Henley E, Higgs J, Williams V. Clinical education program strategies for challenging times. Focus on Health Professional Education: A multidisciplinary Journal. 2000;2(2):1-17.

8. Ladyshewsky RK, Barrie SC, Drake CM. A Comparison of productivity and learning Outcome in Individual and Cooperative Physical therapy Clinical Education Models. Phys Ther. 1998;78(12):1288-301. [PMID 9859948]

9. Australian Association of Occupational Therapists (AAOT). Revised Minimum Standards For The Education Of Occupational Therapists. Perth. World Federation Of Occupational Therapists. 2002.

10. Australian Physiotherapy Council (APC). Australian Standards for Physiotherapy. Safe and Effective Physiotherapy. 2006. www.physiocouncil.com.au

11. American Physical Therapy Association (APTA). Guidelines for Physical Therapists in Occupational Health. 2008. www.apta.org

12. Burt CM. Work evaluation and work hardening. Pedretti, M.B. (Ed.) in Occupational therapy practice skills for physical dysfunction. 226-36. 2001. Sydney: Mosby.

13. Isernhagen SJ. Physical therapy and occupational rehabilitation. J Occup Rehabil. 1991;1(1):71-82.

14. Stuckey R. Enhancing Work Performance in Industrial Settings: A Role for Occupational Therapy. Br J Occup Ther. 1997;60(6):277-8.

15. Walters D. Workplace Arrangements for OHS in the 21st Century. Working Paper10. Paper presented at the Australian OHS Regulation for the 21st Century. 2003.

16. Boucaut R. Physiotherapy student placements in industry: a way of learning about OHS. Journal of Occupational Health Safety, and Environment Australia and New Zealand. 2003;19(2):159-66.

17. James $C$, Prigg A. A self-directed fieldwork program to provide alternative occupational health placements for undergraduate occupational therapy students. Aust Occup Ther J. 2004;51(2):60-8.

18. Harrison K, Allen S. Features of occupational rehabilitation systems in Australia: A map through the maze. Work. 2003; 21(2): 141-151. [PMID 14501092]

19. Jacobsen F, Fink AM, Marcussen V, Larsen K, et al. Interprofessional undergraduate clinical learning: Results from a three year project in a Danish Interprofessional Training Unit. J Interprof Care. 2009;23(1):30-40. [PMID 19142781 ]

20. Thomas J, Clarke B, Pollard K, et al. Facilitating interprofessional enquiry-based learning: Dilemmas and strategies. $J$ Interprof Care. 2007;21(4):463-5. [PMID 17654163]

21. Lincoln MA, McAllister LL. Peer learning in medical education. Med Teach. 1993;15:17-25. [PMID 8326841]

22. Triggs Nemshick M, Shepard KF. Physical therapy clinical education in a 2:1 student-instructor education model. Phys Ther. 1996;76(9):968-81. [PMID 8790275]

23. Lysaght R. Approaches to worker rehabilitation by occupational and physical therapists in the United States: Factors impacting practice. Work. 2004;23:139-46 [PMID 15502294 ]

24. Adam K, Chan C. Creating Diversity by Contrasting Perspectives: Interprofessional Enrichment in Health Service Development. OT Australia Queensland State Conference Brisbane. 21st -22nd November 2009.

25. Law M, Cooper B, Strong S, et al. The Person-Environment-Occupation Model: A transactive approach to occupational performance. Can J Occup Ther.1996;63(1):9-23.

26. Brintnell S, Roxburgh M. Person Environment Occupational Model: An Analysis Tool for Workplace Dynamics. Paper presented at the International Forum on Disability Management. Brisbane, Australia. 2008.

27. IBM SPSS, 20. PASW Statistics Chicago: SPSS Inc. 2011. www.ibm.com/spss_statistics

28. Seigal S. Non-parametrics Statistics: For the Behavioural Sciences. New York: McGraw Hill.1956.

29. McDonald JH. Kruskal-Wallis Test. In Handbook of Biological Statistics. 2nd Edition. Sparky House Publishing. Baltimore, Maryland.2009. Retrieved 29th March 2012 from www./ludel.edu/ mcdonald/statstep.html

30. Howitt, D \& Cramer, D. Thematic Analysis. Chapter 1. In Research Methods in Psychology. Editors Howitt, D. \& Cramer, D. Second Edition, Pearson Education. 2010. Retrieved 30th March 2012. www.wps.pearsoned.co.uk

31. Boucaut R. Undergraduate physiotherapy training in occupational health and safety: a model from the University of South Australia. World Confederation for Physical Therapy. Vancouver, Canada. 2007. 
32. Thorpe K. How to better prepare our graduates for working in occupational rehabilitation: Occupational therapist's perspective. Unpublished Honours Thesis. The University of Western Sydney. School of Exercise and Health Sciences. Sydney. 2004.

33. Hummell J. Effective fieldwork supervision: Occupational therapy student perspectives. Aus Occ Ther J. 1997;44:147-57.

34. Kolb, DA. Learning Styles and Disciplinary Differences. Chapter In Learning Styles and Disciplinary Differences. Ed. Chickering, A.W. 1st edition. The Modern American College, San Francisco: Jossey-Bass. San Francisco.1981. 232-55. 